Jurnal Ilmiah Akuntansi • Vol. 3, No. 2, Hal: 171-192 • Desember 2018

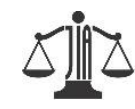

\title{
NIAT UNTUK MENGAMBIL SERTIFIKASI AKUNTAN DENGAN PENGUJIAN THEORY OF PLANNED BEHAVIOR DAN TEORI MOTIVASI
}

\author{
I Gusti Ayu Ratih Permata Dewia, ${ }^{\text {, }}$, Putu Yudha Asteria Putrib, Cok Istri \\ Ratna Sari Dewic \\ a,b,c Universitas Warmadewa, Jl. Terompong No.24, Sumerta Kelod, Denpasar Tim., \\ Kota Denpasar, Bali, Indonesia \\ (ratihpermatadewiiga@yahoo.com)
}

\begin{abstract}
ABSTRAK
Penelitian ini bertujuan untuk menganalisis pengaruh sikap, norma subektif, kontrol perilaku persepsian, pemahaman, motivasi karir, motivasi ekonomi, dan motivasi prestasi terhadap niat mahasiswa untuk mengambil sertifikasi akuntan profesional ACCA, CA dan CPA. Populasi dalam penelitian ini adalah seluruh mahasiswa S1 program studi Akuntansi Universitas di Bali yang berjumlah 10.624 mahasiswa akuntansi dengan sampel sejumlah 100 mahasiswa. Teknik analisis data yang digunakan pada penelitian ini adalah analisis statistik deskriptif, uji asumsi klasik dan pengujian hipotesis menggunakan analisis regresi berganda. Hasil penelitian ini membuktikan bahwa sikap, norma subektif, pemahaman, motivasi karir, dan motivasi prestasiberpengaruh terhadap niat mahasiswa untuk mengambil sertifikasi akuntan profesional ACCA, CA dan CPA. Sedangkan kontrol perilaku persepsian dan motivasi ekonomi tidak berpengaruh terhadap niat mahasiswa untuk mengambil sertifikasi akuntan profesional ACCA, CA dan CPA.
\end{abstract}

Kata Kunci: Theory of Planned Behavior, Teori Motivasi, Sertifikasi Akuntan Profesional

\begin{abstract}
This study aims to analyze the influence of attitudes, subjective norms, perceived behavioral control, understanding, career motivation, economic motivation, and achievement motivation on students' intentions to take the ACCA, CA and CPA professional accountant certification. The population in this study were all undergraduate students of the University of Bali Accounting study program totaling 10,624 accounting students. In this study the authors narrowed the population to the number of students by 10,624 by calculating the sample size which was done using the Slovin technique, so that the sample in this study were 100 students. The data analysis technique used in this research is descriptive statistical analysis, classical assumption test and hypothesis testing using multiple regression analysis. The results of this study prove that attitudes, subjective norms, understanding, career motivation, and achievement motivation affect student intentions to take the ACCA, $C A$ and CPA professional accountant certification. While perceived behavior control and economic motivation do not affect students' intention to take ACCA, CA and CPA professional accountant certification.
\end{abstract}

Keywords: Theory of Planned Behavior, Motivation Theory, Professional Accountant Certification 


\section{PENDAHULUAN}

Sejalan dengan kemajuan pesat dunia teknologi dan informasi, ilmu akuntansi berkembang dengan sangat baik (Andersen, 2012). Di Indonesia, kecenderungan untuk belajar akuntansi meningkat. Hal tersebut diikuti dengan banyaknya lulusan akuntansi dari seluruh perguruan tinggi Indonesia yang setiap tahun diatas angka tiga puluh ribu (www.iaiglobal.or.id). Profesi Akuntan memiliki peranan besar untuk meningkatkan transparansi dan kualitas informasi keuangan demi terwujudnya perekonomian nasional yang sehat dan efisien. Tidak ada proses akumulasi dan distribusi sumber daya ekonomi yang tidak memerlukan campur tangan profesi Akuntan. Profesi Akuntan menyebar di dalam dan di luar instansi pemerintah (www.iaiglobal.or.id). Maka dari itu, peranan profesi akuntan menjadi sangat penting dalam perkembangan ini.

Indonesia sebagai salah satu anggota Association of Southeast Asian Nations (ASEAN) harus siap menghadapi era perdagangan yang dilaksanakan oleh Asean Economic Community (AEC). Pelaksanaan AEC turut menggerakan setiap profesi untuk mempersiapkan berbagai keperluan dalam menyambut era tersebut, termasuk profesi akuntan karena profesi akuntan memiliki peranan besar dalam perekonomian nasional. Dengan adanya AEC, akuntan luar negeri dapat masuk ke Indonesia dengan sangat mudah. Hal tersebut menjadi tantangan bagi profesi akuntan, terkait dengan eksistensi profesi akuntan yang ada di Indonesia terancam dengan keberadaan akuntan dari Negara-negara tetangga yang merupakan anggota ASEAN (www.iaiglobal.or.id). Persaingan ketat yang timbul dalam memperebutkan profesi akuntan di ASEAN, menuntut akuntan untuk memiliki kualitas sertaintegritas yang tinggi dalam menghadapi pasar bebas ASEAN.

MEA berdampak pada beberapa sektor seperti bidang jasa. Salah satu profesi yang terkena dampak dengan adanya MEA yaitu akuntan. Maka dari itu diperlukan akuntan profesional yang diakui secara global agar dapat bersaing dan menghadapi persaingan di era MEA. Indonesia tidak hanya perlu mendorong jumlah akuntan profesional, tetapi juga juga harus diimbangi dengan kualitas profesionalisme akuntan yang mampu 
bersaing di level global (Ayu dan Dhika, 2016).

Indonesia memiliki akuntan profesional yang memenuhi kualitas setara dengan akuntan global. Namun jumlahnya masih kurang. Dalam ASEAN Federation of Accountants (AFA) Report dinyatakan di sebagian besar negara ASEAN masih terjadi kekurangan akuntan profesional. Jumlah akuntan Singapura, Malaysia, dan Thailand lebih banyak daripada Indonesia. Jika kondisi ini tidak diperhatikan lebih lanjut maka, Indonesia berpotensi diserbu oleh akuntan-akuntan dari negara lain (Avianti, 2015).

Tabel 1. Jumlah Akuntan di Berbagai Negara

\begin{tabular}{llll}
\hline Negara & 2014 & 2015 & 2016 \\
\hline Thailand & 63.691 & 68.777 & 71.128 \\
Malaysia & 31.454 & 32.511 & 32.990 \\
Singapura & 28.530 & 24.774 & 31.118 \\
Indonesia & 18.507 & 26.782 & 28.110 \\
\hline
\end{tabular}

Perkembangan dalam dunia yaitu memberikan jasa pendidikan, usaha harus selalu direspon oleh system pendidikan akuntansi agar dapat menghasilkan sarjana akuntansi yang berkualitas dan siap untuk terjun ke dalam dunia kerja (Setyani, 2005). Perguruan tinggi dituntut untuk mampu menghasilkan akuntanakuntan yang handal dan berdaya saing global. Perguruan tinggi juga harus mampu mempersiapkan alumninya untuk memenuhi standar dan persyaratan dalam rangka menghasilkan akuntan yang profesional. Hal ini sesuai dengan kewajiban utama dari perguruan tinggi, penelitian dan pengabdian masyarakat.

Banyak penelitian yang dilakukan untuk mengetahui faktorfaktor mahasiswa akuntansi dalam memilih karier mereka, salah satunya adalah dengan penerapan model Theory of Planned Behavior (TPB). Teori perilaku rencanaan (Theory of Planned Behavior) merupakan pengembangan lebih lanjut dari Theory of Reasoned Action (TRA) yang dicetuskan oleh Ajzen (Jogiyanto, 2007: 62). TRA menjelaskan bahwa perilaku (behavior) dilakukan karena individu memiliki niat atau keinginan untuk melakukannya (behavioralintention). 
Niat seseorang selain dapat diprediksi dengan TPB, juga dapat diprediksi dengan motivasi baik dari dalam dirinya maupun dari luar. Seperti dalam penelitian yang dilakukan oleh Abidin dan Ervanto (2015) menunjukkan bahwa Motivasi karir, motivasi ekonomi, motivasi prestasi berpengaruh signifikan terhadap minat mahasiswa mengikuti ujian CPA, Motivasi gelar tidak berpengaruh signifikan terhadap minat mahasiswa mengkuti ujian CPA.

Penelitian ini bertujuan untuk menganalisis pengaruh sikap, norma subektif, kontrol perilaku persepsian, pemahaman, motivasi karir, ekonomi, dan prestasi pada sertifikasi akuntan profesional ACCA, CAdan CPA terhadap niat mahasiswa untuk mengambil sertifikasi akuntan profesional ACCA, CA dan CPA.

TELAAH LITERATUR DAN PERUMUSAN HIPOTESIS

Teori Perilaku Terencana /Theory of Planned Behavior)

Teori Perilaku Terencana (Theory of Planned Behavior) atau TPB merupakan pengembangan lebih lanjut dari Theory Reasoned Action (TRA). Teori Tindakan Beralasan (Theory of Reasoned Action) didasarkan pada asumsi bahwa manusia biasanya berperilaku dengan cara yang sadar, bahwa mereka mempertimbangkan informasi yang tersedia, dan secara implisit dan eksplisit juga mempertimbangkan implikasi-implikasi dari tindakan-tindakan yang dilakukan (Jogiyanto, 2007).

\section{Teori Motivasi}

Motivasi merupakan dorongan yang terdapat dalam diri seseorang maupun dari luar sehingga seseorang berkeinginan untuk melakukan tingkah laku yang lebih baik dari sebelumnya (Uno, 2014: 9). Mengingat CA (Chartered Accountant) penting bagi mahasiswa akuntansi sebagi calon akuntan maupun bagi akuntan, karena dapat memberikan kontribusi untuk menjadi seorang akuntan profesional yang memiliki daya saing di tingkat global. Maka diperlukan motivasi dari dalam diri mahasiswa terhadap minat untuk memperoleh sertifikasi CA.

\section{Hipotesis Penelitian}

Pengaruh Sikap Terhadap Niat Mahasiswa Untuk Mengambil Sertifikasi Akuntan Profesional ACCA, CA dan CPA Sikap menurut Jogiyanto (2007) adalah evaluasi kepercayaan (belief) atau perasaan positif atau negatif dari seseorang jika harus melakukan perilaku yang akan ditentukan. 
Evaluasi kepercayaan yang mendukung atau tidak mendukung suatu perilaku pada seorang mahasiswa dalam mengambil sertifikasi akuntan profesional adalah perasaan berkaitan dengan suatu perilaku yang membawa manfaat dan keuntungan bagi seorang mahasiswa yang mengambil sertifikasi akuntan ACCA, CA dan CPA.

Penelitian Sumaryono (2016) menemukan hubungan positif dan signifikan, antara sikap pada sertifikasi akuntansi profesional CA terhadap niat mahasiswa untuk mengambil sertifikasi CA mengambil sertifikasi akuntan profesional. Penelitian Trikristriani (2014) menemukan sikap mahasiswa pada akuntan publik berpengaruh positif terhadap intensi mahasiswa akuntansi untuk berkarir menjadi akuntan publik. Sedangkan penelitian Solikhah (2014) menemukan Sikap terhadap CPA dan hukum CPA berpengaruh terhadap niat untuk berkarir sebagai CPA. Oleh karena itu dapat dirumuskan hipotesis sebagai berikut:

H1: Sikap pada sertifikasi akuntan profesional ACCA, CA dan CPA berpengaruh terhadap niat mahasiswa untuk mengambil sertifikasi akuntan profesional ACCA, CA dan CPA.
Pengaruh Norma Subyektif Terhadap Niat Mahasiswa Untuk Mengambil Sertifikasi Akuntan Profesional ACCA, $C A$ dan $C P A$

Pengertian norma subyektif menurut Jogiyanto (2007), adalah persepsi atau pandangan seseorang terhadap kepercayaan-kepercayaan orang lain, yang akan mempengaruhi niat untuk melakukan atau tidak melakukan perilaku yang sedang dipertimbangkan. Untuk mengambil sertifikasi akuntan profesional ACCA, $\mathrm{CA}$ atau $\mathrm{CPA}$, mahasiswa membutuhkan saran dari orang lain yang disebut referent. Referent yang biasa didengarkan oleh seorang mahasiswa yaitu dosen, orang tua, ataupun teman yang sudah lebih awal mengambil sertifikasi akuntan profesional ACCA, CA atau CPA.

Penelitian Sumaryono (2016) menemukan adanya hubungan positif dan signifikan antara norma subyektif pada CA terhadap niat mahasiswa untuk mengambil sertifikasi CA. Selanjutya, penelitian Wardani (2016) menemukan bahwa faktor norma subyektif memiliki pengaruh yang signifikan terhadap niat untuk mengambil Chartered Accountant. Norma subyektif juga ditemukan berpengaruh positif terhadap intensi 
mahasiswa akuntansi untuk berkarir menjadi akuntan publik (Trikristriani, 2014). Sedangkan penelitian Solikhah (2014) menemukan bahwa norma subyektif berpengaruh terhadap niat untuk berkarir sebagai CPA. Oleh karena itu dapat dirumuskan hipotesis sebagai berikut:

H2: Norma subyektif pada sertifikasi akuntan profesional ACCA, CA dan CPA berpengaruh terhadap niat mahasiswa untuk mengambil sertifikasi akuntan profesional ACCA, CA dan CPA.

Pengaruh Kontrol Perilaku Persepsian Terhadap Niat Mahasiswa Untuk Mengambil Sertifikasi Akuntan Profesional ACCA, CA dan CPA

Pengertian kontrol perilaku persepsian menurut Hidayat (2010) adalah persepsi seseorang terhadap kesanggupannya dalam melaksanakan suatu perilaku, di dalamnya ada dua aspek yang diperhatikan yaitu: pertama, seberapa besar orang tersebut memiliki kontrol terhadap suatu perilaku (controllability), dan kedua, seberapa yakin orang tersebut merasa sanggup melakukan suatu perilaku (self-efficacy).

Penelitian Sumaryono (2016) menemukan hubungan positif dan signifikan antara kontrol perilaku persepsian pada CA terhadap niat mahasiswa untuk mengambil sertifikasi CA. Sedangkan penelitian Solikhah (2014) menenukan bahwa kontrol perilaku persepsian berpengaruh terhadap niat untuk berkarir sebagai CPA. Oleh karena itu dapat dirumuskan hipotesis sebagai berikut:

H3: Kontrol perilaku persepsian pada sertifikasi akuntan profesional CA, ACCA dan CPA berpengaruh terhadap niat mahasiswa untuk mengambil sertifikasi akuntan profesional CA, ACCA dan CPA.

Pengaruh Pemahaman Tentang Sertifikasi akuntan profesional ACCA, CA dan CPA Terhadap Niat Mahasiswa Untuk Mengambil Sertifikasi Akuntan Profesional ACCA, CA dan CPA

Pemahaman menurut Arikunto (2009) adalah bagaimana seseorang mempertahankan, membedakan, menduga (estimate), menerangkan, memperluas, menyimpulkan, menggeneralisasikan, memberikan contoh, menuliskan kembali, dan memperkirakan. Ketika mahasiswa bisa membedakan, menerangkan, menyimpulkan dan memperluas informasi tentang sertifikasi akuntan profesional ACCA, CA dan CPA. 
Informasi yang harus dipahami oleh mahasiswa akuntansi yang bisa meningkatkan niat mahasiswa dalam mengambil sertifikasi akuntan profesional yang pertama adalah tentang ACCA, CA dan CPA. Pengertian tentang ACCA, CA dan CPA tersebut berisi informasi tentang bagaimana mengambil sertifikasi akuntan profesional ACCA, CA dan CPA. Pengertian yang kedua adalah tentang Peraturan Menteri Keuangan Nomor 25/PMK.01/2014 yang di dalamnya memuat informasi tentang akuntan beregister negara. Pengertian yang ketiga adalah UU No 5 tahun 2011 yang di dalamnya menjelaskan tentang peraturan untuk menjadi seorang CPA dan peraturan warga negara asing untuk menjadi CPA. Penelitian Sumaryono (2016) yang menemukan hubungan tidak berpengaruh positif dan signifikan antara pemahaman mahasiswa tentang $\mathrm{CA}$ terhadap niat mahasiswa untuk mengambil sertifikasi CA. Oleh karena itu dapat dirumuskan hipotesis sebagai berikut:

H4: Pemahaman tentang sertifikasi akuntan profesional CA, ACCA dan CPA berpengaruh terhadap niat mahasiswa untuk mengambil sertifikasi akuntan profesional CA, ACCA dan CPA.
Pengaruh Motivasi karir Terhadap Niat Mahasiswa Untuk Mengambil Sertifikasi Akuntan Profesional ACCA, CA dan CPA Motivasi karir merupakan dorongan yang timbul dalam diri seseorang untuk meningkatkan kemampuannya untuk mencapai kedudukan, jabatan atau karir yang lebih baik dari sebelumnya (Widyastuti, dkk., 2004). Sehingga motivasi karir dapat dianggap sesuai dengan minat memperoleh sertifikasi CA, karena dapat menjadi pilihan untuk mengembangkan potensi yang telah ada pada lulusan S-1 Akuntansi menjadi lebih baik. CA dapat memberikan kontribusi bagi mahasiswa yang ingin mengembangkan kemampuan di bidang akuntansi. Dalam penelitian Abidin dan Ervanto (2015) mendapatkan hasil bahwa Motivasi karir berpengaruh signifikan terhadap minat mahasiswa mengikuti ujian CPA. Oleh karena itu dapat dirumuskan hipotesis sebagai berikut:

H5: Motivasi karir berpengaruh terhadap niat mahasiswa untuk mengambil sertifikasi akuntan profesional CA, ACCA dan CPA. 
Pengaruh Motivasi Ekonomi Terhadap Niat Mahasiswa Untuk Mengambil Sertifikasi Akuntan Profesional ACCA, $C A$ dan $C P A$

Motivasi ekonomi adalah dorongan yang timbul dalam diri seseorang untuk meningkatkan kemampuannya dalam rangka mencapai penghargaan finansial yang diinginkan (Widyastuti, dkk., 2004). Gaji juga ditentukan oleh tingkat pendidikan dan pengalaman bekerja yang ditekuni, sehingga seseorang akan memperoleh starting salary yang tinggi (Linda dan Muda, 2011). Sehingga motivasi ekonomi dianggap relevan dengan minat mahasiswa memperoleh sertifikasi CA dan menjadi akuntan profesional dengan anggapan bahwa profesi sebagai akuntan profesional dapat menjanjikan dari segi ekonomi.

Dalam penelitian Abidin dan Ervanto (2015) mendapatkan hasil bahwa motivasi ekonomi berpengaruh signifikan terhadap minat mahasiswa mengikuti ujian CPA. Oleh karena itu dapat dirumuskan hipotesis sebagai berikut:

H6: Motivasi ekonomi berpengaruh terhadap terhadap niat mahasiswa untuk mengambil sertifikasi akuntan profesional CA, ACCA dan CPA.
Pengaruh Motivasi Prestasi Terhadap Niat Mahasiswa Untuk Mengambil Sertifikasi Akuntan Profesional ACCA, $C A$ dan $C P A$

Motivasi prestasi menunjukkan bahwa seseorang yang berprestasi di bidang akuntansi sangat cocok dengan kemampuan yang telah ditekuninya tersebut, dan berprofesi sebagai akuntan dengan memperoleh sertifikasi CA dapat menjadi media untuk meningkatkan prestasi yang telah dicapai (Abidin dan Ervanto, 2015). Dalam teori motivasi Mc. Clelland, seseorang dianggap mempunyai kekuatan pada dirinya apabila mempunyai keinginan berprestasi lebih baik daripada yang lain pada banyak situasi (Fahriani, 2012) dan berkeinginan mengambil tugas yang dapat dipertanggungjawabkan (Uno, 2014: 47).

Dalam penelitian Abidin dan Ervanto (2015) menunjukkan bahwa motivasi prestasi berpengaruh signifikan terhadap minat mahasiswa mengikuti ujian CPA. Oleh karena itu dapat dirumuskan hipotesis sebagai berikut:

H7: Motivasi prestasi berpengaruh terhadap terhadap niat mahasiswa untuk mengambil 
sertifikasi akuntan profesional CA, ACCA dan CPA.

\section{METODE PENELITIAN}

Populasi pada penelitian ini adalah seluruh mahasiswa S1 program studi Akuntansi Universitas di Bali yang berjumlah $\quad 10.624$ mahasiswa akuntansi. Dalam penelitian ini penulis mempersempit populasi yaitu jumlah mahasiswa sebanyak 10.624 dengan menghitung ukuran sampel yang dilakukan dengan menggunakan teknik Slovin menurut Sugiyono (2011:87).

Tabel 2. Jumlah Mahasiswa Akuntansi Universitas di Bali

\begin{tabular}{llc}
\hline No & \multicolumn{1}{c}{ Nama Kampus } & $\begin{array}{c}\text { Jumlah Mahasiswa } \\
\text { Akuntansi }\end{array}$ \\
\hline 1 & Universitas Udayana & 1.662 \\
2 & Universitas Pendidikan Ganesha & 1.404 \\
3 & Universitas Warmadewa & 2.298 \\
4 & Universitas Mahasaraswati & 2.846 \\
5 & Universitas Hindu Indonesia & 1.140 \\
6 & Universitas Pendidikan Nasional & 1.247 \\
7 & Universitas Dhyana Pura & 27 \\
& $\quad$ Jumlah & 10.624
\end{tabular}

Sumber: Pangkalan Data Perguruan Tinggi, 2017 (data diolah)

Berikut perhitungan sampel dengan menggunakan rumus slovin:

$\mathrm{n}=$ $1+10.624$ $\mathrm{n}=99,07$ sampel, dibulatkan menjadi 100 sampel keseluruhan.

Variabel dependen (Y) pada penelitian ini adalah niat mahasiswa untuk mengambil sertifikasi akuntan profesional ACCA, CA dan CPA dengan skala Likert yang telah dimodifikasi menjadi 4 jawaban Sangat Setuju (SS), Setuju (S), Tidak Setuju (TS), dan
Sangat Tidak Setuju (STS) dan diproksikan melalui 4 butir pertanyaan. Variabel independen (X) terdiri dari sikap, norma subyektif, kontrol perilaku persepsian, pemahaman, motivasi karir, ekonomi, dan prestasi yang diukur dengan skala Likert 1-4 yaitu Sangat Setuju (SS), Setuju (S), Tidak Setuju (TS), dan Sangat Tidak Setuju (STS). Sumber data yang digunakan dalam penelitian ini merupakan data primer sehingga instrumen penelitian dalam bentuk 
kuesioner. Penelitian ini menggunakan analisis regresi linear berganda.

HASIL DAN PEMBAHASAN

Statistik Deskriptif

Statistik deskriptif merupakan teknik deskriptif yang memberikan informasi mengenai data yang dimiliki dan tidak bermaksud menguji hipotesis. Statistik deskriptif disajikan untuk memberikan informasi mengenai jumlah sampel, nilai minimum, nilai maksimum, nilai rata-rata, dan standar deviasi dari masing-masing variabel.

Tabel 3.Statistik Deskriptif

\begin{tabular}{|c|c|c|c|c|c|}
\hline & $\mathrm{N}$ & Minimum & Maximum & Mean & $\begin{array}{c}\text { Std. } \\
\text { Deviation }\end{array}$ \\
\hline$\overline{\mathrm{Y}}$ & 100 & 4,00 & 14,99 & 12,5259 & $\overline{3,53443}$ \\
\hline $\mathrm{X} 1$ & 100 & 17,98 & 64,75 & 54,0414 & 14,36401 \\
\hline $\mathrm{X} 2$ & 100 & 6,00 & 22,62 & 18,9957 & 5,23222 \\
\hline X3 & 100 & 6,00 & 22,45 & 18,7653 & 5,36733 \\
\hline $\mathrm{X} 4$ & 100 & 11,00 & 41,23 & 34,3995 & 9,29190 \\
\hline $\mathrm{X} 5$ & 100 & 7,00 & 26,04 & 21,9059 & 6,16662 \\
\hline X6 & 100 & 7,00 & 26,56 & 22,0204 & 5,94728 \\
\hline $\mathrm{X} 7$ & 100 & 4,00 & 16,06 & 13,1333 & 3,44292 \\
\hline
\end{tabular}

Valid N

(listwise)

100

Sumber: Data diolah, 2018.

\section{Uji Kualitas Data}

Uji Validitas

Uji validitas digunakan untuk mengukur sah atau valid tidaknya suatu kuesioner. Dalam penelitian ini untuk mengukur validitas digunakan Coeficient corelationpearson yaitu dengan menghitung korelasi antara skor masing-masing butir pertanyaan dengan total skor, Ghozali (2001). Untuk tingkat validitas dilakukan uji signifikansi dengan membandingkan nilai $r$ hitung dengan nilai $r$ tabel. Untuk degree of freedom(df) $=n-k$ dalam hal ini $\mathrm{n}$ adalah jumlah sampel dan $\mathrm{k}$ adalah jumlah konstruk. Pada kasus ini besarnya df dapat dihitung 100-8 atau df = 92 dengan alpha 0,05 didapat $r$ tabel 0,202; jika $r$ hitung (untuk tiap-tiap butir pertanyaan dapat dilihat pada kolom corrected item pertanyaan totalcorrelation) lebih besar 
dari $\mathrm{r}$ tabel dan nilai $\mathrm{r}$ positif, maka valid. butir pertanyaan tersebut dikatakan

Tabel 4. Uji Validitas

\begin{tabular}{|c|c|c|c|}
\hline Variabel & Item & $\begin{array}{c}\text { Pearson } \\
\text { Corelation }\end{array}$ & Status \\
\hline Niat mahasiswa untuk & Y.1 & 0.389 & Valid \\
\hline mengambil sertifikasi & Y.2 & 0.431 & Valid \\
\hline akuntan profesional & Y.3 & 0.475 & Valid \\
\hline \multirow[t]{9}{*}{ ACCA, CA dan CPA } & Y.4 & 0.428 & Valid \\
\hline & $\mathrm{X} 1.1$ & 0.375 & Valid \\
\hline & $\mathrm{X} 1.2$ & 0.378 & Valid \\
\hline & $\mathrm{X} 1.3$ & 0.408 & Valid \\
\hline & $\mathrm{X} 1.4$ & 0.501 & Valid \\
\hline & $\mathrm{X} 1.5$ & 0.421 & Valid \\
\hline & $\mathrm{X} 1.6$ & 0.487 & Valid \\
\hline & $\mathrm{X} 1.7$ & 0.383 & Valid \\
\hline & $\mathrm{X} 1.8$ & 0.384 & Valid \\
\hline \multirow[t]{11}{*}{ Sikap } & $\mathrm{X} 1.9$ & 0.390 & Valid \\
\hline & $\mathrm{X} 1.10$ & 0.405 & Valid \\
\hline & $\mathrm{X} 1.11$ & 0.371 & Valid \\
\hline & $\mathrm{X} 1.12$ & 0.383 & Valid \\
\hline & $\mathrm{X} 1.13$ & 0.448 & Valid \\
\hline & $\mathrm{X} 1.14$ & 0.394 & Valid \\
\hline & $\mathrm{X} 1.15$ & 0.402 & Valid \\
\hline & $\mathrm{X} 1.16$ & 0.367 & Valid \\
\hline & $\mathrm{X} 1.17$ & 0.480 & Valid \\
\hline & $\mathrm{X} 2.1$ & 0.526 & Valid \\
\hline & $\mathrm{X} 2.2$ & 0.552 & Valid \\
\hline \multirow{6}{*}{ Norma subyektif } & $\mathrm{X} 2.3$ & 0.538 & Valid \\
\hline & $\mathrm{X} 2.4$ & 0.509 & Valid \\
\hline & $\mathrm{X} 2.5$ & 0.585 & Valid \\
\hline & X2.6 & 0.496 & Valid \\
\hline & X3.1 & 0.654 & Valid \\
\hline & X3.2 & 0.757 & Valid \\
\hline \multirow{8}{*}{$\begin{array}{l}\text { Kontrol perilaku } \\
\text { persepsian }\end{array}$} & X3.3 & 0.632 & Valid \\
\hline & X3.4 & 0.650 & Valid \\
\hline & X3.5 & 0.712 & Valid \\
\hline & X3.6 & 0.693 & Valid \\
\hline & $\mathrm{X} 4.1$ & 0.738 & Valid \\
\hline & $\mathrm{X} 4.2$ & 0.680 & Valid \\
\hline & $\mathrm{X} 4.3$ & 0.673 & Valid \\
\hline & $X 4.4$ & 0.627 & Valid \\
\hline \multirow[t]{5}{*}{ Pemahaman } & X4.5 & 0.631 & Valid \\
\hline & $X 4.6$ & 0.713 & Valid \\
\hline & $\mathrm{X} 4.7$ & 0.713 & Valid \\
\hline & $\mathrm{X} 4.8$ & 0.693 & Valid \\
\hline & $\mathrm{X} 4.9$ & 0.573 & Valid \\
\hline
\end{tabular}




\begin{tabular}{cccc}
\hline Variabel & Item & $\begin{array}{c}\text { Pearson } \\
\text { Corelation }\end{array}$ & Status \\
\hline \multirow{4}{*}{ Motivasi karir } & X4.10 & 0.586 & Valid \\
& X4.11 & 0.646 & Valid \\
& X5.1 & 0.494 & Valid \\
& X5.2 & 0.612 & Valid \\
& X5.3 & 0.552 & Valid \\
& X5.4 & 0.633 & Valid \\
& X5.6 & 0.631 & Valid \\
& X5.7 & 0.559 & Valid \\
& X6.1 & 0.515 & Valid \\
Motivasi ekonomi & X6.2 & 0.464 & Valid \\
& X6.3 & 0.475 & Valid \\
& X6.4 & 0.431 & Valid \\
& X6.5 & 0.530 & Valid \\
& X6.6 & 0.452 & Valid \\
& X6.7 & 0.421 & Valid \\
& X7.1 & 0.542 & Valid \\
& X7.2 & 0.362 & Valid \\
& X7.3 & 0.583 & Valid \\
& X7.4 & 0.446 & Valid \\
& & & Valid \\
\hline
\end{tabular}

Sumber: Data diolah, 2018.

Dari tabel-tabel di atas dapat diketahui bahwa masing-masing item pertanyaan memiliki $\mathrm{r}$ hitung $>$ dari $\mathrm{r}$ tabel dan bernilai positif. Dengan demikian butir pertanyaan tersebut dinyatakan valid.

Tabel 5.Uji Reliabilitas

\begin{tabular}{llcc}
\hline No & \multicolumn{1}{c}{ Variabel } & Jumlah Item & $\begin{array}{c}\text { Cronbach's } \\
\text { Alpha }\end{array}$ \\
\hline 1 & Niat mahasiswa untuk & 4 & 0.970 \\
& $\begin{array}{l}\text { mengambil sertifikasi } \\
\text { akuntan profesional ACCA, }\end{array}$ & & \\
& CA dan CPA & 17 & \\
2 & Sikap & 6 & 0.990 \\
3 & Norma subyektif & 6 & 0.976 \\
4 & Kontrol perilaku persepsian & 11 & 0.972 \\
5 & Pemahaman & 7 & 0.987 \\
6 & Motivasi karir & 7 & 0.984 \\
7 & Motivasi ekonomi & 4 & 0.968 \\
8 & Motivasi prestasi & & 0.947 \\
\hline
\end{tabular}

Sumber: Data diolah, 2018. 
Uji Reliabilitas

Uji reliabilitas digunakan untuk mengukur suatu kuesioner yang merupakan indikator dari variabel atau konstruk. Berdasarkan tabel 5 dapat diketahui bahwa nilai cronbach alpha masingmasing instrumen yang digunakan dalam penelitian ini adalah $>0,60$ yang mengisyaratkan bahwa data yang dikumpulkan dengan menggunakan instrumen tersebut reliabel.

\section{Uji Asumsi Klasik}

Uji Normalitas

Uji normalitas dimaksudkan untuk menguji apakah dalam model regresi, variabel bebas dan variabel terikatnya, memiliki distribusi normal atau tidak.

Tabel 6.Uji Normalitas

\begin{tabular}{llr}
\hline & & $\begin{array}{c}\text { Unstandardized } \\
\text { Residual }\end{array}$ \\
\hline $\mathrm{N}$ & & 100 \\
Normal Parametersa,b & Mean &, 0000000 \\
& Std. & 1,34363721 \\
Most Extreme & Deviation &, 062 \\
Differences & Absolute &, 062 \\
Test Statistic & Positive &,- 061 \\
Asymp. Sig. (2-tailed) & Negative &, 062 \\
Sumber: Data diolah, 2018.
\end{tabular}

Sumber: Data diolah, 2018.

Berdasarkan Tabel 6 tersebut menunjukkan bahwa Asymp. Sig. (2tailed) sebesar 0,200> dari level of significant $(0,05)$, sehingga dapat disimpulkan variabel dalam penelitian ini berdistribusi normal.

\section{Uji Heteroskedastisitas}

Uji heteroskedastisitas bertujuan untuk mengetahui apakah pada model regresi terjadi ketidaksamaan varian dari residual satu pengamatan ke pengamatan lain.
Berdasarkan Tabel 7 terlihat bahwa tidak ada pengaruh variabel bebas terhadapabsolute residual yang ditunjukkan oleh nilai signifikansi dari setiap variabel yang diuji lebih dari 0,05, dengan demikian model yang dibuat tidak mengandung gejala heteroskedastisitas.

Uji Multikolinearitas

Uji multikolinearitas bertujuan untuk menguji apakah dalam model regresi ditemukan adanya korelasi antar variabel bebas. 
Tabel 7.Uji Heteroskedastisitas

\begin{tabular}{|c|c|c|c|c|c|c|}
\hline \multirow{2}{*}{\multicolumn{2}{|c|}{ Model }} & \multicolumn{2}{|c|}{$\begin{array}{c}\text { Unstandardized } \\
\text { Coefficients } \\
\text { Std. }\end{array}$} & \multirow{2}{*}{$\begin{array}{c}\text { Standardized } \\
\text { Coefficients } \\
\text { Beta }\end{array}$} & \multirow[b]{2}{*}{$\mathrm{t}$} & \multirow[b]{2}{*}{ Sig. } \\
\hline & & $\mathrm{B}$ & Error & & & \\
\hline \multirow[t]{8}{*}{1} & (Constant) & 1,030 &, 123 & & 8,357 & ,000 \\
\hline & $\mathrm{X} 1$ &,- 045 &, 119 &,- 052 &,- 380 & ,705 \\
\hline & $\mathrm{X} 2$ &,- 011 &, 120 &,- 014 &,- 096 &, 924 \\
\hline & X3 & ,018 & ,083 & ,027 & ,219 & ,827 \\
\hline & X4 &, 141 &, 128 &, 148 & 1,100 & 274 \\
\hline & $\mathrm{X} 5$ & ,064 &, 128 & ,072 & ,498 & 619 \\
\hline & X6 &,- 077 &, 112 &,- 094 &,- 687 & ,494 \\
\hline & $\mathrm{X} 7$ &,- 086 &, 078 &,- 125 & $-1,095$ &, 276 \\
\hline
\end{tabular}

Sumber: Data diolah, 2018.

Tabel 8. Uji Multikolinearitas

\begin{tabular}{|c|c|c|c|}
\hline \multirow{2}{*}{\multicolumn{2}{|c|}{ Model }} & \multicolumn{2}{|c|}{$\begin{array}{c}\text { Collinearity } \\
\text { Statistics }\end{array}$} \\
\hline & & Tolerance & VIF \\
\hline \multirow[t]{7}{*}{1} & $\mathrm{X} 1$ & ,388 & 2,577 \\
\hline & $\mathrm{X} 2$ & ,267 & 3,744 \\
\hline & $\mathrm{X} 3$ & , 197 & 5,075 \\
\hline & $\mathrm{X} 4$ & ,348 & 2,870 \\
\hline & X5 & ,254 & 3,930 \\
\hline & X6 & ,235 & 4,248 \\
\hline & $\mathrm{X} 7$ & , 405 & 2,471 \\
\hline
\end{tabular}

Sumber: Data diolah, 2018.

Berdasarkan $\quad$ Tabel $\quad 8 \quad$ terdapat multikolinearitas dalam model menunjukkan bahwa tidak ada variabel bebas yang memiliki nilai tolerance kurang dari 0,1 dan tidak ada yang memiliki nilai VIF lebih dari 10. Jadi, dapat disimpulkan bahwa tidak ini.

Model persamaan regresi linear berganda penelitian ini adalah sebagai berikut: $\mathrm{Y}=-1.143+0.040 \mathrm{X} 1+$ $0,103 \mathrm{X} 2+0.078 \mathrm{X} 3+0.058 \mathrm{X} 4+0.138$ $\mathrm{X} 5+0.052 \mathrm{X} 6+0.148 \mathrm{X} 7$ 


\section{Pembahasan Hasil Penelitian}

Pengaruh Sikap Terhadap Niat Mahasiswa Untuk Mengambil Sertifikasi Akuntan Profesional ACCA, CA dan CPA

Berdasarkan Tabel 9dapat dilihat bahwa nilai $t$ hitung untuk variabel profitabilitas adalah sebesar 0.040 dan nilai probabilitas signifikansi sebesar 0,013<0,05. Hal ini berarti bahwa $\mathrm{H}_{1}$ diterima.

Hasil penelitian ini sesuai dengan penelitian yang dilakukan olehSumaryono (2016) serta penelitian Suciati dan Laksmi (2017) yang menjelaskan sikap berpengaruh positif dan signifikan terhadap niat mahasiswauntuk mengambil sertifikasi akuntan profesional. Penelitian Trikristriani (2014) dan Solikhah (2014)yang menjelaskan bahwa sikap berpengaruh terhadap niat mahasiswa untuk berkarir menjadi akuntan publik.

Sikap menurut Jogiyanto (2007) adalah evaluasi kepercayaan (belief) atau perasaan positif atau negatif dari seseorang jika harus melakukan perilaku yang akan ditentukan. Evaluasi kepercayaan yang mendukung atau tidak mendukung suatu perilaku pada seorang mahasiswa dalam mengambil sertifikasi akuntan profesional adalah perasaan berkaitan dengan suatu perilaku yang membawa manfaat dan keuntungan bagi seorang mahasiswa yang mengambil sertifikasi akuntan ACCA, CA dan CPA.

Tabel 9.Hasil Analisis Regresi Linear Berganda

\begin{tabular}{lrrr}
\hline \multicolumn{1}{c}{ Variabel } & $\begin{array}{c}\text { Koefesien } \\
\text { Regresi (B) }\end{array}$ & $\mathrm{t}$ & Sig. \\
\hline X1 & 0.040 & 2.524 & 0.013 \\
X2 & 0.103 & 1.985 & 0.050 \\
X3 & 0.078 & 1.335 & 0.185 \\
X4 & 0.058 & 2.257 & 0.026 \\
X5 & 0.138 & 3.067 & 0.003 \\
X6 & 0.052 & 1.075 & 0.285 \\
X7 & 0.148 & 2.320 & 0.023 \\
Konstanta & -1.143 & & \\
Adjusted R Square & 0,844 & & \\
F Hitung & 77.799 & & \\
Signifikansi F & 0,000 & & \\
\hline
\end{tabular}

Sumber: Data diolah, 2018. 
Pengaruh Norma Subyektif Terhadap Niat Mahasiswa Untuk Mengambil Sertifikasi Akuntan Profesional ACCA, CA dan CPA

Berdasarkan Tabel 9 dapat dilihat bahwa nilai $t$ hitung untuk variabel profitabilitas adalah sebesar 0.103 dan nilai probabilitas signifikansi sebesar $0,05 \leq 0,05$. Hal ini berarti bahwa $\mathrm{H}_{2}$ diterima.

Hasil penelitian ini sesuai dengan penelitian yang dilakukan olehSumaryono (2016), Wardani (2016), Solikhah (2014), Trikristiani (2014) serta penelitian Suciati dan Laksmi (2017) yang menemukan bahwa norma subyektif berpengaruh terhadap niat mahasiswa untuk mengambil sertifikasi akuntan profesional.

Pengertian norma subyektif menurut Jogiyanto (2007), adalah persepsi atau pandangan seseorang terhadap kepercayaan-kepercayaan orang lain, yang akan mempengaruhi niat untuk melakukan atau tidak melakukan perilaku yang sedang dipertimbangkan. Untuk mengambil sertifikasi akuntan profesional ACCA, $\mathrm{CA}$ atau $\mathrm{CPA}$, mahasiswa membutuhkan saran dari orang lain yang disebut referent. Referent yang biasa didengarkan oleh seorang mahasiswa yaitu dosen, orang tua, ataupun teman yang sudah lebih awal mengambil sertifikasi akuntan profesional ACCA, CA atau CPA.

Pengaruh Kontrol Perilaku Persepsian Terhadap Niat Mahasiswa Untuk Mengambil Sertifikasi Akuntan Profesional ACCA, CA dan CPA

Berdasarkan Tabel 9dapat dilihat bahwa nilai $\mathrm{t}$ hitung untuk variabel profitabilitas adalah sebesar 0.078 dan nilai probabilitas signifikansi sebesar 0,185>0,05. Hal ini berarti bahwa $\mathrm{H}_{3}$ ditolak.

Hasil penelitian ini yang menunjukkan bahwa kontrol perilaku persepsian berpengaruh tidak berpengaruh terhadap niat mahasiswa untuk mengambil sertifikasi akuntan professionalkonsisten dengan penelitian Wardani (2016) serta penelitian Suciati dan Laksmi (2017) yang menemukan bahwa kontrol perilaku persepsian tidak memiliki pengaruh yang signifikan terhadap niat mahasiswa untuk mengambil sertifikasi akuntan profesional. Sementara itu, penelitian ini menunjukkan hasil yang berbeda dari Sumaryono (2016), Solikhah (2014) dan Trikristiani (2014) yang menyatakan bahwa kontrol perilaku persepsian memiliki pengaruh positif terhadap niat mahasiswa untuk mengambil 
sertifikasi akuntan profesional.

Ditolaknya hipotesis ini diduga karena mahasiswa memiliki persepsi bahwa mereka tidak memiliki kemampuan, sumber daya dan kesempatan untuk mengambil sertifikasi akuntan profesional ACCA, CA dan CPA dan hal ini dapat menurunkan niat mahasiswa untuk mengambil sertifikasi akuntan profesional ACCA, CA dan CPA.

Pengaruh Pemahaman Tentang Sertifikasi akuntan profesional ACCA, CA dan CPA Terhadap Niat Mahasiswa Untuk Mengambil Sertifikasi Akuntan Profesional ACCA, CA dan CPA

Berdasarkan Tabel 9dapat dilihat bahwa nilai $t$ hitung untuk variabel profitabilitas adalah sebesar 0.058 dan nilai probabilitas signifikansi sebesar 0,026<0,05. Hal ini berarti bahwa $\mathrm{H}_{4}$ diterima.

Pemahaman menurut Arikunto (2009) adalah bagaimana seseorang mempertahankan, membedakan, menduga (estimate), menerangkan, memperluas, menyimpulkan, menggeneralisasikan, memberikan contoh, menuliskan kembali, dan memperkirakan. Ketika mahasiswa bisa membedakan, menerangkan, menyimpulkan dan memperluas informasi tentang sertifikasi akuntan profesional ACCA, CA dan CPA.
Informasi yang harus dipahami oleh mahasiswa akuntansi yang bisa meningkatkan niat mahasiswa dalam mengambil sertifikasi akuntan profesional yang pertama adalah tentang ACCA, CA dan CPA. Pengertian tentang ACCA, CA dan CPA tersebut berisi informasi tentang bagaimana mengambil sertifikasi akuntan profesional ACCA, CA dan CPA. Pengertian yang kedua adalah tentang Peraturan Menteri Keuangan Nomor 25/PMK.01/2014 yang di dalamnya memuat informasi tentang akuntan beregister negara. Pengertian yang ketiga adalah UU No 5 tahun 2011 yang di dalamnya menjelaskan tentang peraturan untuk menjadi seorang CPA dan peraturan warga negara asing untuk menjadi CPA.

Pengaruh Motivasi karir Terhadap Niat Mahasiswa Untuk Mengambil Sertifikasi Akuntan Profesional ACCA, CA dan CPA Berdasarkan Tabel 9dapat dilihat bahwa nilai $t$ hitung untuk variabel profitabilitas adalah sebesar 0.138 dan nilai probabilitas signifikansi sebesar 0,003<0,05. Hal ini berarti bahwa $\mathrm{H}_{5}$ diterima.

Hasil penelitian ini sesuai dengan penelitian yang dilakukan olehAbidin dan Ervanto (2015) mendapatkan hasil bahwa Motivasi 
karir berpengaruh signifikan terhadap minat mahasiswa mengikuti ujian CPA. Motivasi karir merupakan dorongan yang timbul dalam diri seseorang untuk meningkatkan kemampuannya untuk mencapai kedudukan, jabatan atau karir yang lebih baik dari sebelumnya (Widyastuti, dkk., 2004). Sehingga motivasi karir dapat dianggap sesuai dengan minat memperoleh sertifikasi CA, karena dapat menjadi pilihan untuk mengembangkan potensi yang telah ada pada lulusan S-1 Akuntansi menjadi lebih baik. CA dapat memberikan kontribusi bagi mahasiswa yang ingin mengembangkan kemampuan di bidang akuntansi

Pengaruh Motivasi Ekonomi Terhadap Niat Mahasiswa Untuk Mengambil Sertifikasi Akuntan Profesional ACCA, CA dan CPA

Berdasarkan Tabel 9dapat dilihat bahwa nilai $t$ hitung untuk variabel profitabilitas adalah sebesar 0.052 dan nilai probabilitas signifikansi sebesar 0,285>0,05. Hal ini berarti bahwa $\mathrm{H}_{6}$ ditolak.

Motivasi ekonomi tidak berpengaruh terhadap niat mahasiswa untuk mengambil sertifikasi akuntan profesional CA, ACCA dan CPA. Motivasi ekonomi merupakan dorongan dari dalamdiri seseorang untuk meningkatkan kemampuannya dalam rangka mencapai penghargaan finansial yang diinginkan (Widyastuti, dkk., 2004). Motivasi ekonomi seperti kesempatan untuk meningkatkan status ekonomi, mendapatkan tunjangan keluarga, gaji awal yang tinggi, mendapatkan kenaikan gaji, mendapatkan program dana pensiun, gaji yang besar, bonus akhir tahun tidak cukup mampu membuat mahasiswa untuk berminat memperoleh sertifikasi akuntan profesional, dikarekanakan anggapan bahwa untuk meningkatkan status ekonomi, mendapatkan tunjangan keluarga, gaji awal yang tinggi, mendapatkan kenaikan gaji, mendapatkan program dana pensiun, gaji yang besar, bonus akhir tahun tidak hanya dapat diperoleh dengan mempunyai sertifikasi akuntan profesional, tetapi bisa melalui bidang lain. Hal ini disebabkan karena faktor dalam diri mahasiswa tersebut yang tidak terdorong untuk mencari penghargaan finansial atau ekonomi tetapi lebih terdorong untuk mengerjakan sesuatu yang mereka sukai daripada bila bekerja hanya karena imbalan (Fahriani, 2012). Mungkin juga disebabkan karena 
berkarir di bidang lain memberikan penghasilan yang tinggi dari pada berkarir sebagai akuntan profesional (Puspitarini dan Kusumawati, 2011).

Pengaruh Motivasi Prestasi Terhadap Niat Mahasiswa Untuk Mengambil Sertifikasi Akuntan Profesional ACCA, CA dan CPA

Berdasarkan Tabel 9dapat dilihat bahwa nilai $t$ hitung untuk variabel profitabilitas adalah sebesar 0.148 dan nilai probabilitas signifikansi sebesar $0,023<0,05$. Hal ini berarti bahwa $\mathrm{H}_{7}$ diterima.

Hasil penelitian ini sesuai dengan penelitian yang dilakukan olehAbidin dan Ervanto (2015) menunjukkan bahwa motivasi prestasi berpengaruh signifikan terhadap minat mahasiswa mengikuti ujian CPA.

Motivasi prestasi menunjukkan bahwa seseorang yang berprestasi di bidang akuntansi sangat cocok dengan kemampuan yang telah ditekuninya tersebut, dan berprofesi sebagai akuntan dengan memperoleh sertifikasi CA dapat menjadi media untuk meningkatkan prestasi yang telah dicapai (Abidin dan Ervanto, 2015). Dalam teori motivasi Mc. Clelland, seseorang dianggap mempunyai kekuatan pada dirinya apabila mempunyai keinginan berprestasi lebih baik daripada yang lain pada banyak situasi (Fahriani, 2012) dan berkeinginan mengambil tugas yang dapat dipertanggungjawabkan (Uno, 2014: 47).

\section{KESIMPULAN, IMPLIKASI DAN KETERBATASAN PENELITIAN}

\section{Simpulan}

Berdasarkan hasil analisis data yang telah diuraikan di atas dapat ditarik beberapa kesimpulan yaitu sikap, norma subektif, pemahaman, motivasi karir, dan motivasi prestasiberpengaruh terhadap niat mahasiswa untuk mengambil sertifikasi akuntan profesional ACCA, CA dan CPA.Sedangkan kontrol perilaku persepsian dan motivasi ekonomi tidak berpengaruh terhadap niat mahasiswa untuk mengambil sertifikasi akuntan profesional ACCA, CA dan CPA.

\section{Saran}

1) Penelitian selanjutnya diharapkan dapat menambah jumlah sampel atau memperluas daerah penelitian agar diperoleh hasil yang lebih bervariasi.

2) Penelitian selanjutnya diharapkan dalam mengumpulkan data didukung melalui wawancara sehingga responden dapat 
Dewi, Putri, Dewi - Niat untuk Mengambil Sertifikasi Akuntan...

memberikan informasi yang

mendekati keadaan yang

sebenarnya.

3) Bagi pihak IAI dalam hal ini bagi pihak-pihak terkait seperti dosen agar lebih memperkenalkan mengenai berbagai sertifikasi antara lain Ak, CA, CPA, CMA dan memberikan motivasi bagi mahasiswa untuk meningkatkan kemampuannya setelah lulus S1.

\section{REFERENSI}

Abidin, A.Z dan Ervanto, A.D. 2015. Pengaruh motivasi terhadap minat mahasiswa akuntansi mengikuti ujian certified public accountant (CPA). Jaffa. ISSN: 2339-2886 3(1):55-68.

Ajzen, Icek. (2012). "The Theory of Planned Behavior. In P. A. M. Lange, A. W. Kruglanski \& E. T. Higgins (Eds.)". Handbook of Theories of Socialpsychology (Vol. 1, pp. 438-459). London, UK: Sage.

Andersen, W. 2012. "Analisis Persepsi Mahasiswa Akuntansi dalam Memilih Profesi sebagai Akuntan". Skripsi. Universitas Diponegoro.

Arikunto, S. 2009. Dasar-Dasar Evaluasi Pendidikan (edisi revisi). Jakarta: Bumi Aksara.

Arisudana, I. 2009. Intensi Berbagi Pengetahuan ditinjau dari Ekstraversi, Sikap, Norma Subjektif, dan Kontrol Perilaku yang Dipersepsikan. Tesis. Fakultas Psikologi UGM.

Avianti, I. 2015. Peluang dan tantangan akuntan di era MEA. Simposium Nasional Akuntansi (SNA) XVIII Medan, 17 September 2015.

Ayu, D dan Dhika, T. 2016. CA tentukan kesuksesanmu. Http://www.suaraekonomi.com/ ca-Tentukan-Kesuksesanmu/.

Fahriani, D. 2012. Pengaruh motivasi terhadap minat mahasiswa akuntansi untuk mengikuti pendidikan profesi akuntansi (PPAk). Jurnal Ilmu \& Riset Akuntansi 1(12):1-22.

IAI. 2015. Pedoman peserta ujian chartered accountant Indonesia.

Jogiyanto Hartono. 2007. Sistem Informasi Keperilakuan Edisi Revisi. Yogyakarta: Andi.

Linda dan Muda, I. 2011. Pengaruh pengetahuan akuntansi dan motivasi terhadap minat mahasiswa akuntansi perguruan tinggi negeri dan swasta di Propinsi Nanggroe Aceh Darusalam untuk mengikuti pendidikan profesi akuntansi (PPAk). Jurnal Keuangan \& Bisnis 3(2).

Setiyani, Rediana. (2005)."FaktorFaktor yang Membedakan Mahasiswa Akuntansi dalam Memilih Profesi sebagai Akuntan Publik dan NonAkuntan Publik. (Studi Empiris Pada Mahasiswa Akuntansi Perguruan Tinggi Negeri di Pulau Jawa)". Tesis. Program Studi magister Sains Universitas Diponegoro. 
PMK. 2014. Peraturan menteri keuangan republik Indonesia nomor

25/PMK.01/2014.www.iaiglobal. or.id/v03/image/ca/PMK\%2OAk untan\%202014.pdf 1-36.

Solikhah, B. 2014. An application of theory of planned behavior towards CPA Career in Indonesia. Procedia - Social and Behavioral Sciences, 164(August), 397-402. Diakses pada tanggal 13 Oktober 2016, pukul 12:00. Dari https://doi.org/10.1016/j.sbspr o.2014.11.094.

Suciati, Indah dan Ayu Chairina Laksmi. Faktor-Faktor Yang Mempengaruhi Niat Pengambilan Sertifikasi Akuntan. SNA XX Jember 27-30 September 2017.

Sumaryono. 2016. Pengujian Pengaruh Theory of Planned Behavior dan Tingkat Pemahaman Mengenai Chartered Accountant Terhadap Niat Mahasiswa Untuk Mengambil Sertifikat Chartered Accountant. Skripsi. Universitas Negeri Yogyakarta.

Sulistiani, Dewi. (2012). "Faktor-faktor yang Mempengaruhi Niat Mahasiswa untuk Berkarier sebagai Akuntan Publik: Aplikasi Theory of PlannedBehavior". Skripsi. Program Akuntansi Universitas Diponegoro.

Trikristiani, Yohanna Fajar. (2014). "Pengujian Theory of Planned Behavior dan Pengaruh Pemahaman terhadap UndangUndang Nomor 5 Tahun 2011 tentang Akuntan Publik terhadap Intensi Mahasiswa Akuntansi untuk Berkarier Menjadi Akuntan Publik". Skripsi. Program Studi
Akuntansi Universitas Negeri Yogyakarta.

Uno, H.B. 2014. Teori motivasi \& pengukurannya. 1st ed. Jakarta: Bumi Aksara.

Wardani, G. A. S. 2016. Niat untuk mengambil chartered accountant dengan theory of planned behavior. Skripsi. Universitas Diponerogo.

Widyastuti, S.W, Suryaningsum S, dan Juliana K. 2004. Pengaruh motivasi terhadap minat mahasiswa akuntansi untuk mengikuti pendidikan profesi akuntansi (PPAk). SNA VII Denpasar-Bali, 2-3 Desember. 